\title{
Transcriptional Profiling of Synovial Macrophages Using Minimally Invasive Ultrasound-Guided Synovial Biopsies in Rheumatoid Arthritis
}

Arthur M. Mandelin II, ${ }^{1}$ Philip J. Homan, ${ }^{1}$ Alexander M. Shaffer, ${ }^{1}$ Carla M. Cuda, ${ }^{1}$ Salina T. Dominguez, ${ }^{1}$ Emily Bacalao, ${ }^{1}$ Mary Carns,${ }^{1}$ Monique Hinchcliff, ${ }^{1}$ Jungwha Lee, ${ }^{1}$ Kathleen Aren, ${ }^{1}$ Anjali Thakrar, ${ }^{1}$ Anna B. Montgomery, ${ }^{1}$ S. Louis Bridges Jr., ${ }^{2}$ Joan M. Bathon, ${ }^{3}$ John P. Atkinson, ${ }^{4}$ David A. Fox, ${ }^{5}$ Eric L. Matteson, ${ }^{6}$ Christopher D. Buckley, ${ }^{7}$ Costantino Pitzalis, ${ }^{8}$ Deborah Parks, ${ }^{4}$ Laura B. Hughes, ${ }^{2}$ Laura Geraldino-Pardilla, ${ }^{3}$ Robert Ike, ${ }^{5}$ Kristine Phillips, ${ }^{5}$ Kerry Wright, ${ }^{6}$ Andrew Filer, ${ }^{7}$ Stephen Kelly, ${ }^{8}$ Eric M. Ruderman, ${ }^{1}$ Vince Morgan, ${ }^{1}$ Hiam Abdala-Valencia, ${ }^{1}$ Alexander V. Misharin, ${ }^{1}$ G. Scott Budinger, ${ }^{1}$ Elizabeth T. Bartom, ${ }^{1}$ Richard M. Pope, ${ }^{1}$ Harris Perlman, ${ }^{1}$ and Deborah R. Winter ${ }^{1}$

Objective. Currently, there are no reliable biomarkers for predicting therapeutic response in patients with rheumatoid arthritis (RA). The synovium may unlock critical information for determining efficacy, since a reduction in the numbers of sublining synovial macrophages remains the most reproducible biomarker. Thus, a clinically actionable method for the collection of synovial tissue, which can be analyzed using high-throughput strategies, must become a reality. This study was undertaken to assess the feasibility of utilizing synovial biopsies as a precision medicine-based approach for patients with RA.

Supported by the NIH (grant AR-064313 to Dr. Cuda and grants AR-064546, HL-134375, AG-049665, and UH2-AR-067687), a Pfizer ASPIRE award (to Dr. Pope), the United States-Israel Binational Science Foundation (grant 2013247), the Rheumatology Research Foundation (grant Agmt 05/06/14 to Dr. Perlman), and in part by the Arthritis National Research Foundation (grant to Dr. Winter). Dr. Perlman's work was also supported by the Northwestern University Feinberg School of Medicine Mabel Greene Myers Professorship in Medicine and donations to the Rheumatology Precision Medicine Fund.

${ }^{1}$ Arthur M. Mandelin II, MD, PhD, Philip J. Homan, PhD, Alexander M. Shaffer, BA, Carla M. Cuda, PhD, Salina T. Dominguez, BA, Emily Bacalao, BA, Mary Carns, MS, Monique Hinchcliff, MD, Jungwha Lee, PhD, Kathleen Aren, BA, Anjali Thakrar, BA, Anna B. Montgomery, PhD, Eric M. Ruderman, MD, Vince Morgan, BA, Hiam Abdala-Valencia, PhD, Alexander V. Misharin, MD, PhD, G. Scott Budinger, MD, Elizabeth T. Bartom, PhD, Richard M. Pope, $\mathrm{MD}$, Harris Perlman, PhD, Deborah R. Winter, PhD: Northwestern University Feinberg School of Medicine, Chicago, Illinois; ${ }^{2} \mathrm{~S}$. Louis Bridges Jr., MD, PhD, Laura B. Hughes, MD: University of Alabama at Birmingham; ${ }^{3}$ Joan M. Bathon, MD, Laura Geraldino-Pardilla, MD: Columbia University, New York, New York; ${ }^{4}$ John P. Atkinson, MD, Deborah Parks, MD: Washington University School of Medicine, St. Louis, Missouri; ${ }^{5}$ David A. Fox, MD, Robert Ike, MD, Kristine Phillips, MD: University of Michigan School of Medicine, Ann Arbor;
Methods. Rheumatologists at 6 US academic sites were trained in minimally invasive ultrasound-guided synovial tissue biopsy. Biopsy specimens obtained from patients with RA and synovial tissue from patients with osteoarthritis (OA) were subjected to histologic analysis, fluorescence-activated cell sorting, and RNA sequencing (RNA-seq). An optimized protocol for digesting synovial tissue was developed to generate high-quality RNA-seq libraries from isolated macrophage populations. Associations were determined between macrophage transcriptional profiles and clinical parameters in RA patients.

Results. Patients with RA reported minimal adverse effects in response to synovial biopsy. Comparable

\footnotetext{
${ }^{6}$ Eric L. Matteson, MD, Kerry Wright, MD: Mayo Clinic College of Medicine and Science, Rochester, Minnesota; ${ }^{7}$ Christopher D. Buckley, $\mathrm{MD}, \mathrm{PhD}$, Andrew Filer, $\mathrm{MD}, \mathrm{PhD}$ : University of Birmingham Research Laboratories, Queen Elizabeth Hospital Birmingham, Birmingham, UK; ${ }^{8}$ Costantino Pitzalis, MD, Stephen Kelly, MD: William Harvey Research Institute and Barts and The London School of Medicine and Dentistry, Queen Mary University of London, London, UK.

Drs. Mandelin and Homan and Mr. Shaffer contributed equally to this work.

Address correspondence to Richard M. Pope, MD, Northwestern University, Feinberg School of Medicine, Department of Medicine, Division of Rheumatology, 240 East Huron Street, Room M320, Chicago, IL 60611 (e-mail: rmp158@northwestern.edu); or to Harris Perlman, $\mathrm{PhD}$, Northwestern University, Feinberg School of Medicine, Department of Medicine, Division of Rheumatology, 240 East Huron Street, Room M314, Chicago, IL 60611 (e-mail: h-perlman@northwestern.edu); or to Deborah R. Winter, PhD, Northwestern University, Feinberg School of Medicine, Department of Medicine, Division of Rheumatology, 240 East Huron Street, Room M309, Chicago, IL 60611 (e-mail: Deborah.winter@northwestern.edu).

Submitted for publication March 17, 2017; accepted in revised form February 8, 2018.
} 
RNA quality was observed from synovial tissue and isolated macrophages between patients with $\mathrm{RA}$ and patients with OA. Whole tissue samples from patients with RA demonstrated a high degree of transcriptional heterogeneity. In contrast, the transcriptional profile of isolated RA synovial macrophages highlighted different subpopulations of patients and identified 6 novel transcriptional modules that were associated with disease activity and therapy.

Conclusion. Performance of synovial tissue biopsies by rheumatologists in the US is feasible and generates high-quality samples for research. Through the use of cutting-edge technologies to analyze synovial biopsy specimens in conjunction with corresponding clinical information, a precision medicine-based approach for patients with RA is attainable.

Despite the many therapies available for patients with rheumatoid arthritis (RA), there is little information to guide selection of the most effective treatment for an individual patient. Forty-six percent of patients with RA respond (defined as 50\% improvement based on the American College of Rheumatology criteria [ACR50]) to conventional disease-modifying antirheumatic drugs (DMARDs) $(1,2)$ or conventional DMARDs plus antitumor necrosis factor (anti-TNF) therapy (3-11). However, $20-40 \%$ of patients in clinical trials never demonstrate even a minimal response (never meet the ACR20 response criteria) (7-11). Based on a population of $>300$ million in the US, a disease prevalence of $0.6 \%$, and a course of 3-4 months per biologic DMARD therapy, as much as $\$ 2.5$ billion is wasted annually on inadequate therapy $(12,13)$. There is a clear need to develop precision-based therapy for patients with RA, whereby clinical information such as novel biomarkers will enhance our ability to predict the therapeutic response and thereby limit ineffective therapy.

Previous studies have linked macrophages to the pathogenesis of RA. Synovial macrophages are highly activated, express elevated levels of Toll-like receptor 2 (TLR$2)$, TLR-4, and TLR-7 $(14,15)$, and contribute directly and indirectly to synovial inflammation and the destruction of cartilage and bone through the production of degradative enzymes, cytokines, and chemokines. Further, TLR-2, TLR-3, and TLR-7 play essential roles in the development of inflammatory arthritis in mice (16-18). More importantly, macrophages are the central producers of interleukin-1 $\beta$ (IL-1 $\beta$ ), IL-6, and TNF, which comprise the 3 essential proinflammatory cytokines that contribute to RA pathogenesis. To date, approved therapies, including antiTNF, anti-IL-6, JAK inhibitors, CTLA-4Ig, and anti-
CD20, have all been shown to decrease synovial inflammation and bone destruction and, more importantly, reduce macrophage numbers in the synovial sublining (19-21). Despite the fact that synovial macrophages were discovered more than a half-century ago and are crucial for RA pathogenesis (22), surprisingly very little is known about them.

Biomarkers that indicate sensitivity or resistance to a particular therapy are sorely lacking in RA. For the most part, researchers have used peripheral blood, with minimal success, to identify biomarkers for predicting a response to therapy (23). Similarly, the results of genetic approaches have been disappointing (24). More recent studies suggest that the synovium, as the target organ in RA, may have greater potential in determining therapeutic response (23). Currently, the most well-known and reproducible biomarker for response to RA therapy is a reduction in the number of sublining synovial macrophages, determined by immunohistochemical analysis of synovial tissue (25). While arthroscopy has been the most commonly used method to obtain synovial tissue before and after therapy (26-32) and yields substantial amounts of synovial tissue, it is invasive, requires surgical suites, and is expensive, thus limiting its usefulness in clinical practice and clinical studies. Synovectomy and joint replacement surgery are other common mechanisms for researchers to obtain synovial tissue, but patients undergoing these procedures typically exhibit end-stage disease characteristics and samples likely do not reflect the overall pathophysiology at the time when therapeutic decisions are made, prior to progressive joint damage.

Ultrasound technology has advanced significantly and is widely used by rheumatologists as a mechanism for determining the degree of synovitis and inflammation, detecting erosions, and identifying sites for therapeutic injection (33). Over the past decade, ultrasound has been used to facilitate the collection of synovial tissue (29). Minimally invasive ultrasound-guided synovial tissue biopsies have been performed for research purposes throughout Europe, and the standardization for these procedures has been fully evaluated $(23,29,34-46)$. However, there are currently no published studies from the US describing the use of ultrasound-guided synovial tissue biopsies for research. The potential reasons that this technique has not been commonly adopted for research in the US include a lack of training, differences in the medical system and patient populations between Europe and the US, and a lack of "buy-in" from rheumatologists who would recommend the procedure to their patients.

We assembled a consortium of established academic rheumatology groups in the US, including the University of Alabama at Birmingham, Columbia University, Mayo Clinic, Washington University, University of 
Michigan, and Northwestern University, to form the RhEumatoid Arthritis SynOvial tissue Network (REASON). Our consortium was trained in minimally invasive ultrasound-guided synovial biopsy techniques in the UK and has since performed more than 41 biopsies on RA patients with active disease in the US. RNA was extracted from whole synovial tissue and from synovial macrophages isolated by fluorescence-activated cell sorting (FACS) for RNA sequencing (RNA-seq) analysis. The transcriptional profiles of isolated macrophages were used to distinguish between RA patient groups and identify modules of co-regulated genes that were associated with clinical disease and medication. We believe that these studies demonstrate the utility of isolating individual populations of cells within the synovium to understand the pathobiology of the disease and to establish a precision medicine-based approach for RA patients.

\section{PATIENTS AND METHODS}

Patients. Adult patients with RA, diagnosed according to either the ACR 1987 criteria (47) or ACR/European League Against Rheumatism 2010 criteria (48), were selected as candidates for ultrasound-guided synovial biopsy based on the presence of palpable synovitis documented by clinical examination $(49,50)$. To increase the uniformity of the collected tissue, only wrists were sampled in this study. Candidate joints were scanned with standard 2-dimensional B-mode ultrasound with and without Doppler (SonoSite M-MSK with a 15-6 MHz linear probe; FujiFilm SonoSite), and were included in the study if they had a grayscale synovitis score of $\geq 2$ on a 4-point scale (35). Exclusion criteria included uncontrolled comorbid diseases, anticoagulation therapy (low-dose aspirin and nonsteroidal antiinflammatory drugs [NSAIDs] were allowed), use of systemic steroids in excess of prednisone $10 \mathrm{mg}$ daily or equivalent, administration of intramuscular steroids within the previous 4 weeks or intraarticular steroids into the target joint within the past 8 weeks, chronic or recurrent infection, intolerance to lidocaine or chlorhexidine, inability to communicate effectively in English, and membership in a vulnerable population (prisoners, pregnant women, etc.).

Training for ultrasound-guided synovial biopsy. The REASON consortium was created to adopt ultrasound-guided synovial biopsy for research purposes in the US. Rheumatologists from REASON who were experienced in ultrasonography traveled to the UK for a 2-day training session with Drs. Andrew Filer, Christopher D. Buckley, Stephen Kelly, and Costantino Pitzalis on ultrasound-guided synovial biopsy. This session included observation of ultrasound-guided synovial biopsies followed by a practice session using cadavers. Following the training session, the rheumatologists from REASON attended 2 additional practice sessions using cadavers at Northwestern University for refresher training.

Ultrasound-guided synovial biopsy procedure. Procedures were performed either in examination rooms in outpatient rheumatology clinics or in a designated research space. After the presence of synovitis was re-confirmed by sonographic criteria as described above using customary non-sterile techniques, patients were dressed in a laboratory cover-up or examination gown, surgical mask, and surgical hair net. Rheumatologists performing the biopsy were in surgical scrubs with cap, mask, sterile surgical gown, and sterile gloves. The ultrasound probe was placed in a sterile cover. The patient's hand and arm were scrubbed with chlorhexidine from the fingertips to the mid-forearm, and the patient then placed the hand palm down onto a surgical wrist support in a prepared sterile field. The arm was draped in a sterile manner with a fenestrated sheet centered on the wrist, and sterile ultrasound gel was applied.

Ultrasound scanning over the dorsal aspect of the wrist joint in both the longitudinal and transverse planes was then used to locate the region of greatest synovitis in the wrist, usually immediately dorsal/superficial to either the proximal or the distal row of carpal bones. A wheal of lidocaine was used to anesthetize the skin at the ulnar aspect of the wrist. While monitoring the procedure under ultrasound in real time with the probe in the transverse position, an initial ultrasound-guided lidocaine pass into the target joint was made with a 25 -gauge $\times$ 1.5 -inch needle. A second ultrasound-guided lidocaine pass was made into the same wound and needle track with an 18-gauge $\times$ 1.5-inch needle to ensure anesthesia and a clear path for the biopsy device. Care was taken to avoid neurovascular structures and tendons, especially the extensor digiti minimi. An appropriately sized Quick-Core Biopsy needle (Cook Medical) was then selected based on the target wrist (usually 18 gauge $\times 9 \mathrm{~cm}$, with $10-\mathrm{mm}$ throw) and introduced into the same needle track.

Using continuous real-time ultrasound imaging, the jaw of the device was positioned within the synovium (defined by Outcome Measures in Rheumatology [51] as intraarticular, hypoechoic, non-displaceable, poorly compressible tissue) at the point of its greatest abundance, usually between the common extensor tendon bundle and the underlying carpal row. The device was triggered and removed. The sample was removed from the device by scraping with a sterile 21-gauge needle and placed into phosphate buffered saline (PBS) (Thermo Fisher). The process was repeated to obtain a total of 12 samples. Not all biopsy passes yielded tissue; most procedures resulted in 1-3 "empty passes," and thus most patients underwent a total of 13 15 passes to obtain 12 samples of synovium. All samples were taken through the same skin wound but with varying positions of the jaw of the device within the region of most abundant synovitis, with the intent of sampling the entire chosen region uniformly. Variations in the position of the device also included variations in the radial orientation of the jaw with respect to the axis of the device. For example, some samples were taken from 12 o'clock, closer to the extensor tendon bundle, and some from 6 o'clock, closer to the carpal row.

At the completion of the procedure the biopsy site was washed, and after confirming hemostasis, an adhesive bandage was applied to the single puncture wound. None of the patients needed a suture. Patients were instructed in routine after-care and encouraged to use over-the-counter acetaminophen for any discomfort, with permission to escalate to over-the-counter NSAIDs if needed. Patients were instructed to contact the research team by telephone to report any adverse events, including delayed healing or pain not controlled with over-the-counter agents as described above. Most procedures lasted a total of 4560 minutes from the non-sterile scout imaging to the patient departing the procedure room. Patients did not require conscious sedation and were sent home immediately with no postprocedure observation or recovery period and no activity restrictions. 
Tolerability. Tolerability of the procedure was assessed by questionnaires administered before and after the procedure as previously described (36). Patients were asked to rate pain, swelling, and stiffness on a 10-point visual analog scale (VAS). After the procedure, patients were also asked by questionnaire to rate their discomfort during the procedure (none, mild, moderate, or severe) and to rate their likelihood to agree to undergo another procedure (very likely, somewhat likely, unsure, somewhat unlikely, or very unlikely).

Tissue preparation and flow cytometric analysis. From the 12 pieces of synovial tissue obtained per patient by needle biopsies, 4 were selected at random and placed into $10 \%$ neutral buffered formalin for histologic analysis, 4 more randomly selected pieces were placed into RNAlater (Ambion) for whole tissue processing, and the remaining 4 were placed into PBS for tissue digestion. Osteoarthritis (OA) synovial tissue was received from the National Disease Research Interchange and was shipped in Dulbecco's modified Eagle's medium and antibiotics overnight on wet ice. Only soft tissues containing meniscus and synovium were processed. OA synovial tissue was processed identically to tissue from patients with RA.

The length of digestion (30-60 minutes) and intensity of mechanical disaggregation before and after incubation were varied to optimize macrophage isolation. Mechanical disaggregation was performed on a gentleMACS Dissociator (Miltenyi Biotec). The pre-set gentleMACS programs m_lung_01 and $\mathrm{m}$ brain 01 were used to test moderate and aggressive mechanical disaggregation, respectively. Sorted macrophages used for analysis were processed by infusing tissue with a digestion buffer (RPMI 1640 [Sigma], Liberase TL [0.1 mg/ml; Roche], and DNase $[0.1 \mathrm{mg} / \mathrm{ml}$; Roche]) and minced with scissors. Tissue suspensions were transferred to C-tubes (Miltenyi Biotec) and incubated for 1 hour at $37^{\circ} \mathrm{C}$ with aggressive disaggregation before and after incubation. The digestion reaction was quenched with magnetic-activated cell sorter (MACS) buffer (Miltenyi Biotec), and the tissue suspension was filtered over a 40-micron filter. Red blood cells were lysed (BD Pharm Lyse) and then washed twice with Hanks' balanced salt solution (Thermo Fisher). Cells were counted (Invitrogen Countess) and stained with a viability dye $\left(0.5 \mu \mathrm{l} / \mathrm{ml}\right.$ for 15 minutes at $25^{\circ} \mathrm{C}$ in the dark) (data are available upon request from the corresponding author). Cells were then washed twice with MACS buffer, incubated with Fc block (BD Biosciences) $\left(6 \mu \mathrm{l} / 60 \mu \mathrm{l}\right.$ total volume; maximum of $5 \times 10^{6}$ cells for 15 minutes at $4^{\circ} \mathrm{C}$ in the dark), stained with antibody cocktail (for 30 minutes at $4^{\circ} \mathrm{C}$ in the dark) (data are available upon request from the corresponding author), washed twice, resuspended in MACS buffer, and kept on ice until sorted.

Synovial macrophages (CD45+, CD11b+, HLA-DR+, CD15-, CD1c-, CD206+) were sorted on a BD FACSAria Sorp instrument (BD Biosciences) at the Northwestern University Robert H. Lurie Comprehensive Cancer Center Flow Cytometry Core Facility. Cells from RA synovial biopsies were sorted directly into $100 \mu \mathrm{l}$ PicoPure RNA extraction buffer (Arcturus Bioscience). Cells $(>10,000)$ from OA tissues were sorted into cold MACS buffer (Miltenyi Biotec) and immediately centrifuged at $4^{\circ} \mathrm{C}$. Supernatant was removed, and cells were resuspended in $100 \mu \mathrm{l}$ PicoPure RNA extraction buffer. All cells were stored at $-80^{\circ} \mathrm{C}$ until RNA was extracted.

Histopathologic and immunohistochemical analysis. The 4 biopsy pieces fixed in $10 \%$ neutral buffered formalin for histologic analysis were stored overnight and submitted to the Pathology Core Facility at Northwestern University. Paraffin-embedded tissue sections were stained with hematoxylin and eosin $(\mathrm{H} \& \mathrm{E})$ and for CD45 or CD68. Slide images were taken at $40 \times$ and $100 \times$ magnification using an Olympus BX41 microscope and Olympus DP21 camera. Since not all samples subjected to this procedure demonstrate synovial lining, other characteristics including CD45 and CD68 staining were included to provide a semiquantitative or qualitative analysis of inflammation in the biopsied tissue. RA synovial biopsy sections stained with $\mathrm{H} \& \mathrm{E}$ or with antibodies to either CD45 or CD68 antigens were scored for the percent synovium of all 4 pieces of tissue. The CD45 and CD68 scores were determined using a modified scoring system of $0-4$ that indicates the percent of CD45 or CD68 positivity in identified synovium (35). All scoring was performed by an experienced rheumatologist (RMP) who was blinded with regard to the origin of the samples.

Preparation of the RNA library. RNA was isolated from whole synovial tissue by homogenizing tissue with $3.0 \mathrm{~mm}$ of highimpact zirconium beads and a BeadBlaster 24 microtube homogenizer (Benchmark Scientific). RNA was extracted from the cell homogenate using a Qiagen Plus Mini kit. RNA from sorted macrophages was extracted using a PicoPure RNA isolation kit according to the instructions of the manufacturer (Arcturus). RNA quality and quantity were measured using a High-Sensitivity RNA ScreenTape System (Agilent Technologies). Whole synovial tissue RNA-seq libraries were prepared from $90 \mathrm{ng}$ of total RNA using a NEBNext Ultra Kit with poly(A) enrichment. RNA-seq libraries from sorted macrophage populations were prepared using a SMART-Seq v4 Ultra Low Input RNA Kit (Clontech Laboratories) followed by Nextera XT protocol (Illumina). RNA-seq libraries were sequenced on a NextSeq 500 instrument (Illumina) with $\sim 5-10 \times 10^{6}$ aligned reads per sample. A commercially available universal human RNA reference was prepared along with the synovial RNA to represent background RNA expression.

RNA-seq analysis. RNA-seq data were de-multiplexed using bcl2fastq, and RNA-seq reads were aligned to the human reference genome (NCBI, hg19) using TopHat2 (version 2.17.1.14) aligners (52). Gene coverage of samples was calculated using the RSeQC package (53). Sample complexity was calculated using the samtools makeTagDirectory command and identifying the uniquely aligned positions compared to the number of aligned reads. Normalized gene counts were calculated using HTSeq (54). For our analysis, we focused on genes in which at least 2 samples had $\log _{2}$ (fragments per kilobase per million [FPKM]) expression $>3$. For visualization, GENE-E software (https://software.broadinstitute.org/GENE-E/) was used to generate Pearson's pairwise correlation matrices and to perform K-means and hierarchical clustering. Differential gene expression between RA and OA samples in the whole tissue data set was determined using the edgeR Bioconductor package parameters as previously described (adjusted $P<0.01)(55,56)$. Gene Ontology (GO) associations were determined by GOrilla (57). To account for the increased noise of the low-input macrophagespecific RNA-seq, we focused our analysis on genes in which at least 2 samples had $\log _{2}(\mathrm{FPKM}+1)$ expression $>5$, and lower values were set to 5 . We defined differentially expressed genes across patients with RA as those with an adjusted range ( $\log _{2}$ fold change between the second highest and second lowest samples) $>1$. We removed genes driven by 1 outlier sample (defined as genes where the difference between the maximum and second highest values was greater than the difference between the second highest and second lowest values), leaving 553 genes for the analysis. Modules were identified by clustering genes using Kmeans clustering and calculating pairwise Pearson's correlation 
between each gene. The enrichment or depletion of modules within each patient was determined by a Kolmogorov-Smirnov test comparing the expression level of genes in a given module to all 553 genes (with $P$ values less than 0.05 considered significant).

Statistical analysis. Associations between RNA-seq expression patterns in patients and clinical parameters, including disease duration, swollen joint count (SJC), tender joint count (TJC), early disease (defined as a disease duration of $<2$ years), rheumatoid factor (RF), anti-cyclic citrullinated peptide (anti$\mathrm{CCP}$ ) antibodies, and history of treatment with biologic agents or methotrexate, were determined (Table 1). Disease duration, SJC, and TJC were recorded as continuous variables. Early disease, RF, anti-CCP antibodies, and patient medication history were recorded as categorical data (either positive or negative). Patients were divided into 2 groups based on global gene expression data, and associations of patient treatment and clinical data with group 1 and group 2 were determined using Fisher's exact test for categorical variables and Student's $t$-test for continuous variables. Pearson's correlation was used to determine the association between the patient's median gene expression for each module and continuous variables. The $\log _{2}$ fold change of the average median module expression between patients with a positive value and those with a negative value was used to calculate associations with categorical variables (data are available upon request from the corresponding author). Significant changes in gene expression were determined using Student's $t$-test.

\section{RESULTS}

Patient demographics. The REASON consortium was created to adopt ultrasound-guided synovial biopsy for research purposes in the US. Over 2 years, we recruited 41 patients with RA from REASON sites for ultrasound-guided synovial biopsies. Patient demographics, clinical data, and other pertinent information are presented in Table 1.

Table 1. Patient characteristics and sample data*

\begin{tabular}{|c|c|c|c|}
\hline Patient characteristics & & $\begin{array}{l}\text { Histologic findings in RA synovial biopsy } \\
\text { specimens, mean } \pm \text { SEM }(\mathrm{n}=30) \ddagger\end{array}$ & \\
\hline Age, years $(n=41)$ & $57.5 \pm 11.4$ & $\%$ synovial tissue & $36.0 \pm 5.6$ \\
\hline Sex, no. (\%) female/male & $29(71) / 12(29)$ & CD45 score (range $0-4$ ) & $1.7 \pm 0.2$ \\
\hline Disease duration, years $(n=40)$ & $9.3 \pm 8.4$ & CD68 score (range 0-4) & $1 \pm 0.1$ \\
\hline Early disease, no. $(\%)(\mathrm{n}=40) \dagger$ & $9(23)$ & RNA sequencing data, mean \pm SEM & \\
\hline $\begin{array}{l}\text { Rheumatoid factor positive, } \\
\text { no. }(\%)(\mathrm{n}=40)\end{array}$ & $23(58)$ & $\begin{array}{l}\text { Whole tissue samples }(\mathrm{n}=9 \mathrm{RA} \text { and } 9 \text { OA) } \\
\text { RIN }\end{array}$ & \\
\hline Anti-CCP positive, no. $(\%)(\mathrm{n}=36)$ & $19(53)$ & RA & $6.7 \pm 0.5$ \\
\hline ESR, mm/hour $(\mathrm{n}=14)$ & $33.5 \pm 21.7$ & OA & $8.0 \pm 0.2$ \\
\hline DAS28 $(n=17)$ & $4.7 \pm 1.3$ & Number of aligned reads, million & \\
\hline CDAI $(n=20)$ & $21.5 \pm 10.6$ & RA & $9.2 \pm 0.7$ \\
\hline RAPID3 $(\mathrm{n}=25)$ & $11.4 \pm 7.4$ & $\mathrm{OA}$ & $12.9 \pm 1.1$ \\
\hline PGA $(n=24)$ & $4.7 \pm 3.1$ & $\%$ of total reads aligned & \\
\hline HAQ $(\mathrm{n}=18)$ & $0.7 \pm 0.5$ & RA & $81.9 \pm 1.2$ \\
\hline $\operatorname{TJC}(\mathrm{n}=31)$ & $5.8 \pm 6.0$ & OA & $85.3 \pm 1.2$ \\
\hline $\operatorname{SJC}(\mathrm{n}=31)$ & $7.1 \pm 4.9$ & $\%$ complexity & \\
\hline Treatment, no. $(\%)(\mathrm{n}=31)$ & & RA & $54.8 \pm 1.7$ \\
\hline No treatment & $3(10)$ & OA & $56.2 \pm 1.9$ \\
\hline Methotrexate & & Sorted macrophage samples $(\mathrm{n}=15 \mathrm{RA}$ and 9 OA) & \\
\hline Current & $15(48)$ & Cells sorted & \\
\hline Past & $9(29)$ & RA & $1,642 \pm 1,178$ \\
\hline TNF inhibitor & & OA & $77,414 \pm 26,413$ \\
\hline Current & $12(38)$ & Number of aligned reads, million & \\
\hline Past & $17(55)$ & RA & $21.0 \pm 4.2$ \\
\hline IL-6 inhibitor & & OA & $21.1 \pm 6.8$ \\
\hline Current & $2(6)$ & $\%$ of total reads aligned & \\
\hline Past & $2(6)$ & RA & $53.9 \pm 6.0$ \\
\hline JAK inhibitor & & $\mathrm{OA}$ & $65.2 \pm 1.5$ \\
\hline Current & $3(10)$ & $\%$ complexity & \\
\hline Past & $5(16)$ & RA & $37.2 \pm 2.7$ \\
\hline Other treatment & & $\mathrm{OA}$ & $38.1 \pm 2.2$ \\
\hline Current & $11(35)$ & & \\
\hline Past & $12(39)$ & & \\
\hline Prednisone $<5 \mathrm{mg}$, current & $1(3)$ & & \\
\hline Prednisone $5-10 \mathrm{mg}$, current & $6(19)$ & & \\
\hline
\end{tabular}

* Except where indicated otherwise, values are the mean \pm SD. Anti-CCP $=$ anti-cyclic citrullinated peptide; ESR $=$ erythrocyte sedimentation rate; DAS28 = Disease Activity Score in 28 joints; CDAI = Clinical Disease Activity Index; RAPID3 = Routine Assessment of Patient Index Data 3; PGA = physician's global assessment; HAQ = Health Assessment Questionnaire; TJC = tender joint count; SJC = swollen joint count; TNF = tumor necrosis factor; IL-6 = interleukin-6; RA = rheumatoid arthritis; OA = osteoarthritis; RIN = RNA integrity number.

$\dagger$ Disease duration of $<2$ years.

\$ All slides were scored by the same physician (RMP), who was blinded with regard to the origin of the samples. The amount of synovial tissue in each biopsy specimen was estimated by analysis of structure, lining, and leukocyte content. 
A

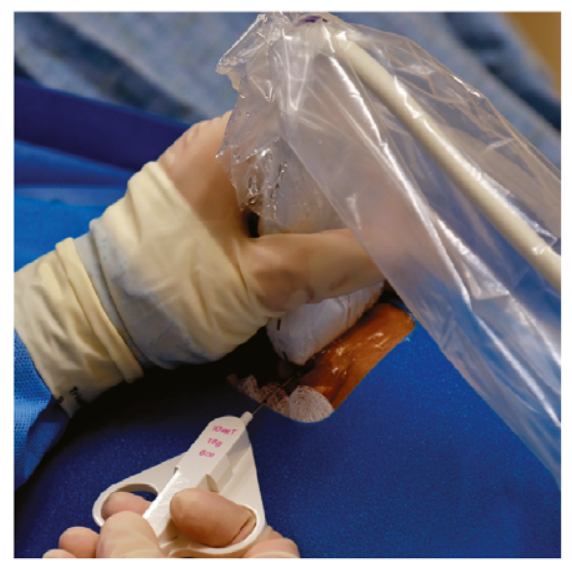

B

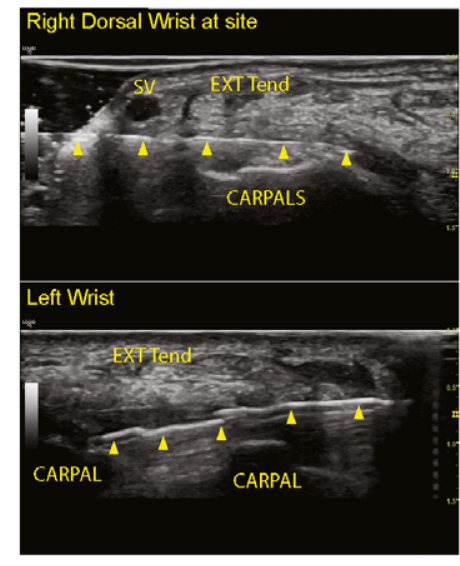

C
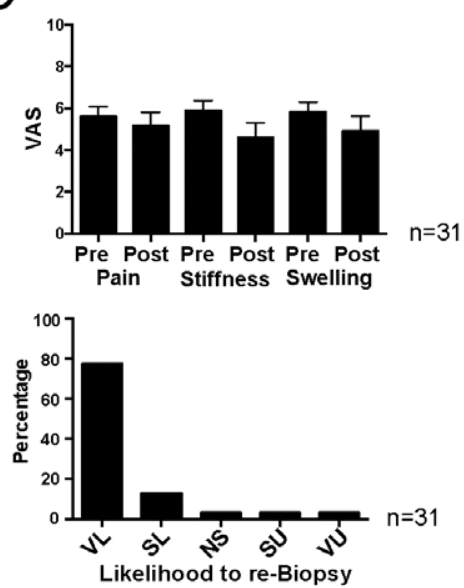

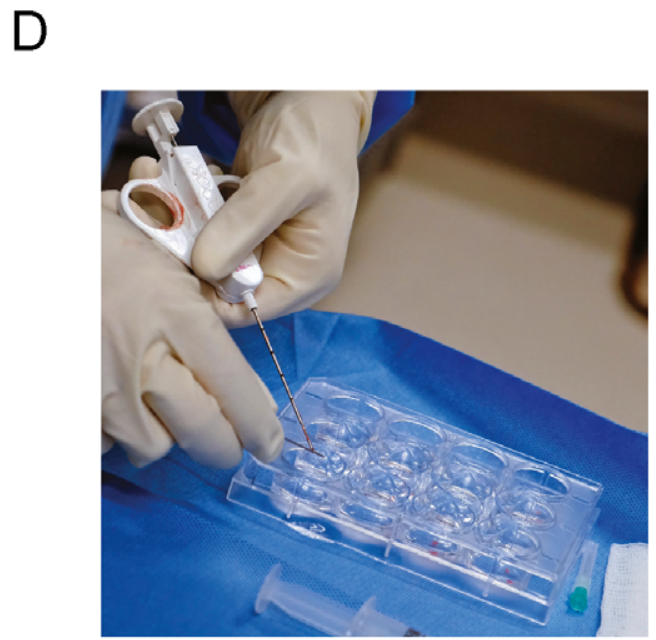

$\mathrm{E}$

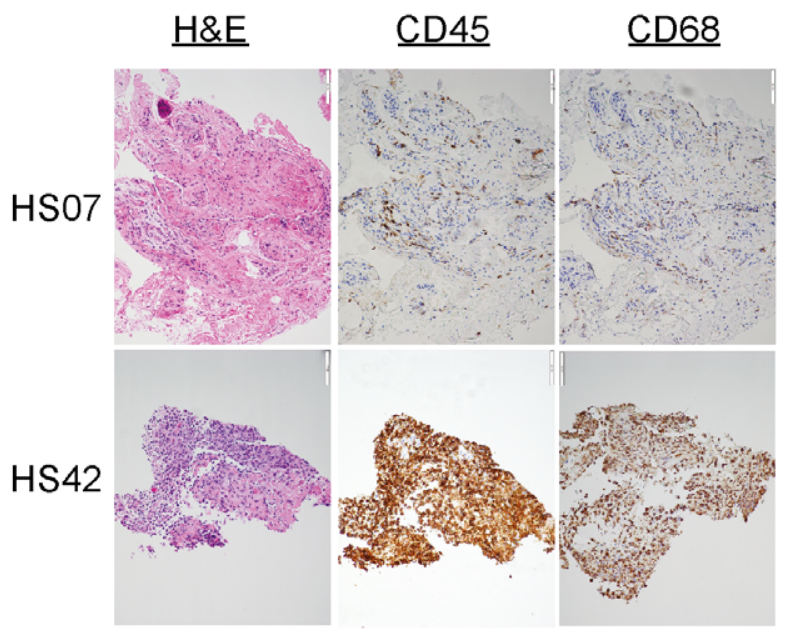

Figure 1. Acquisition and analysis of synovial tissue from patients with rheumatoid arthritis (RA). A, Ultrasound-guided synovial biopsy of an inflamed wrist using an 18-gauge $\times 1.5$-inch needle. B, Dorsal transverse (axial) view of a right wrist showing a needle track created with a 25 gauge $\times 1.5$-inch needle (arrowheads) and a left wrist in which an 18-gauge $\times 9$-cm needle biopsy device has been introduced into the needle track with a 10-mm throw opened (second and third arrowheads from the left). SV = superficial vein; Ext Tend = extensor tendon complex; Carpals = proximal row of carpal bones. C, Top, Patient-reported pain, stiffness, and swelling before and after the biopsy procedure on a visual analog scale (VAS) of 1-10. Bars show the mean \pm SEM. Bottom, Patient-reported likelihood of agreeing to a subsequent procedure. VL $=$ very likely; $\mathrm{SL}=$ somewhat likely; NS = not sure; SU = somewhat unlikely; VU = very unlikely. $\mathbf{D}$, Removal of synovial tissue from the biopsy device. Tissue was placed into phosphate buffered saline on ice until processed. E, Histomorphologic features of synovial biopsy specimens obtained from 2 representative RA patients. Representative photomicrographs of sections stained with hematoxylin and eosin (H\&E), anti-CD45 (for hematopoietic cells), and anti-CD68 antibodies (for macrophages) are shown. HS07 = human sample 07.

Safety and tolerability of ultrasound-guided synovial biopsy. Real-time ultrasound images were used to guide placement of the needle device for biopsy within the synovium of the dorsal side of the wrist (Figures 1A and B). Thirty-one of the 41 patients responded with complete preprocedure and postprocedure VAS assessments of pain, stiffness, and swelling of the biopsied wrist. There were no differences between the preprocedure and postprocedure scores in these patients (Figure 1C). Patients were then asked to rate their likelihood of agreeing to repeat the procedure, and $90.3 \%$ of the patients reported that they would be very likely or somewhat likely to repeat the biopsy, while only $6.5 \%$ stated that they would be somewhat or very unlikely to have a repeat biopsy (Figure 1C).

Histologic assessment of synovial tissue. The quality of the synovial biopsy specimens obtained from patients with RA was first quantified by histologic assessment of tissue structure, presence of synovial lining, and leukocytes (Table 1 and Figures 1D and E). Importantly, all but 5 samples contained synovial tissue $(>10 \%)$, and 
11 biopsy specimens contained $\geq 50 \%$ synovial tissue. The abundance of CD45-positive and CD68-positive cells in each sample was scored on a modified scale of 0 4 (35), revealing a substantial enrichment of hematopoietic cells and, more specifically, macrophages in most biopsy samples (Table 1).

RNA-seq analysis of whole tissue synovial biopsy specimens. The fidelity of the complementary DNA library created from whole synovial tissue obtained from
RA synovial biopsy specimens or from OA patients following whole joint replacement was assessed by a variety of criteria (Table 1). The quality of the RNA-seq data for whole tissue samples was determined by plotting the number of detectable genes at varying FPKM thresholds across samples. There was no observable difference between the number of genes expressed in RA versus OA samples (Figure 2A). The read density over the length of genes revealed that all samples had comparable coverage
A

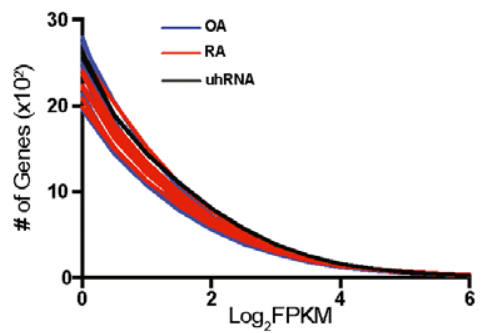

D
B
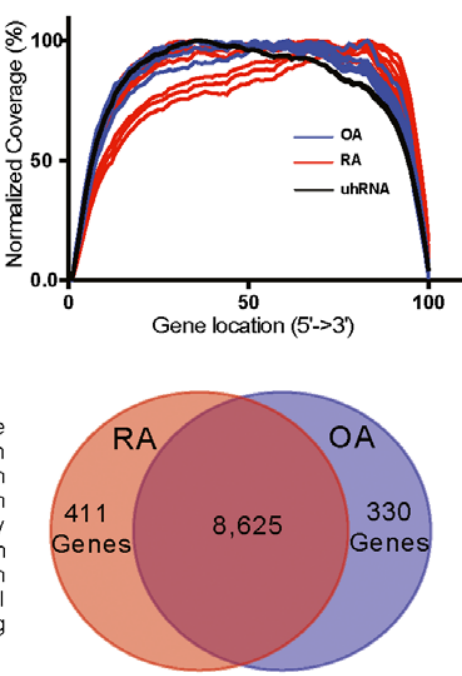

C Tissue
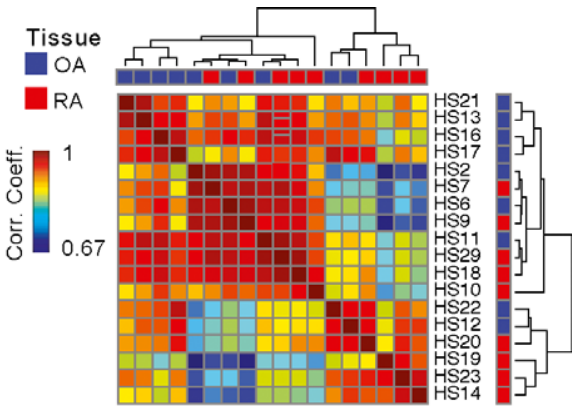

\section{GO Processes In OA}

positive regulation of fibroblast proliferation regulation of osteoblast differentiation regulation of bone remodeling neg. regulation of cartilage development regulation of phosphatidylinositol 3-kinase signaling regulation of ERK1 and ERK2 cascade cellular response to glucocorticoid stimulus response to epidermal growth factor regulation of apoptotic process
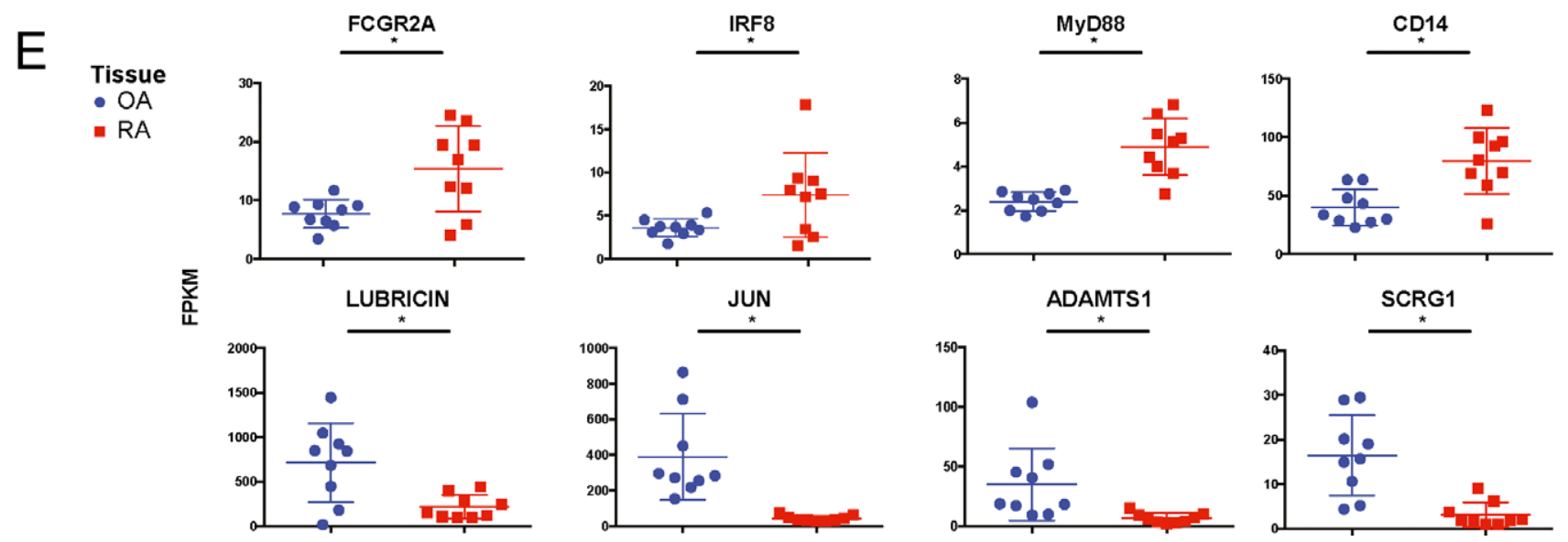

Figure 2. Analysis of whole tissue RNA sequencing libraries. A, Number of genes with an expression level greater than a given $\log _{2}$ (fragments per kilobase per million [FPKM]) value for each osteoarthritis (OA), rheumatoid arthritis (RA), and universal human RNA (uhRNA) control sample. B, Gene coverage plot displaying the average read density across genes from $5^{\prime}$ to $3^{\prime}$. C, Pairwise Pearson's correlations of gene expression between individual patient samples. Samples are organized by hierarchical clustering based on their Pearson's correlation coefficients (corr. coeff.) across samples. Numbers to the right of the matrix are the patient numbers for each sample. HS21 = human sample 21 . D, Venn diagram of the genes expressed in RA and OA samples. The differential analysis (adjusted $P<0.01$ ) revealed 411 and 330 genes that were preferentially expressed in RA and OA tissue, respectively. Select processes from gene ontology (GO) enrichment analysis of genes preferentially expressed in each tissue type are listed. E, Normalized gene expression of individual genes in RA versus OA samples. Symbols represent individual samples; horizontal lines and error bars show the median and interquartile range. ${ }^{*}=$ adjusted $P<0.01$. 
A
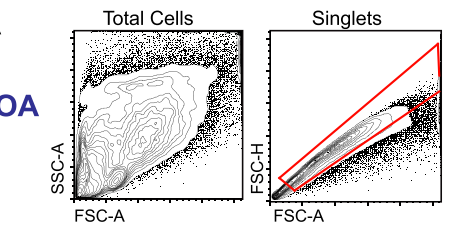

RA
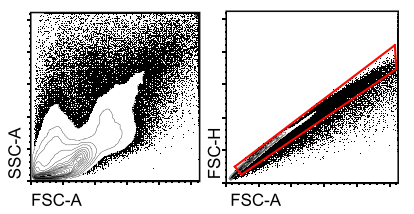

B

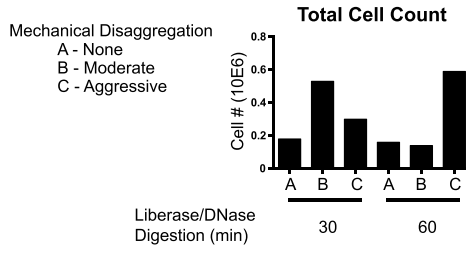

C

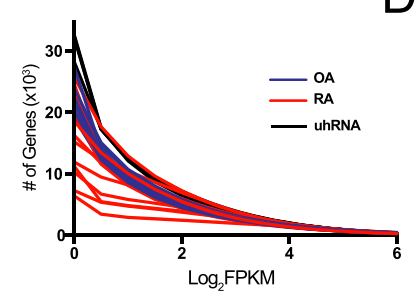

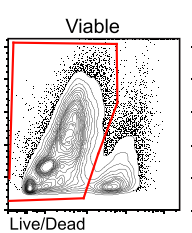
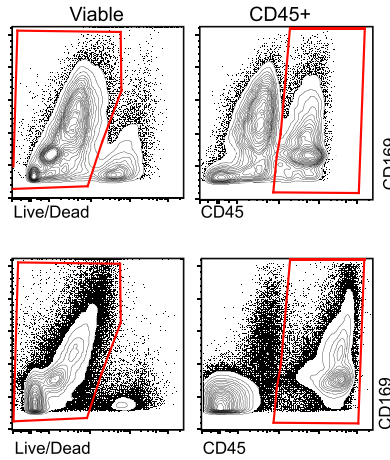

Viable
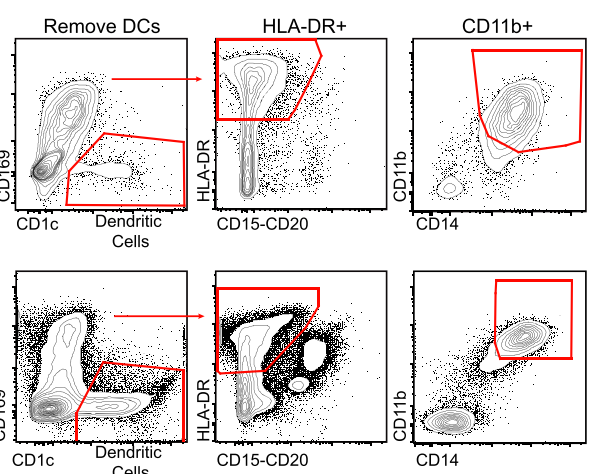

CD45
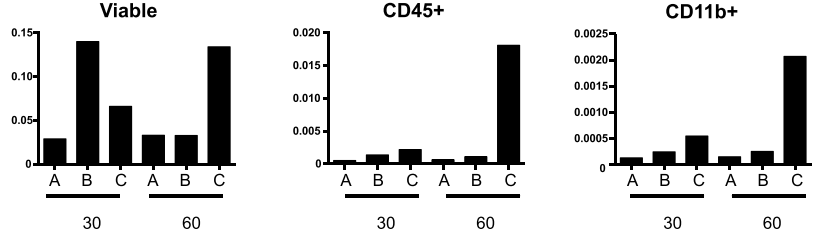

E
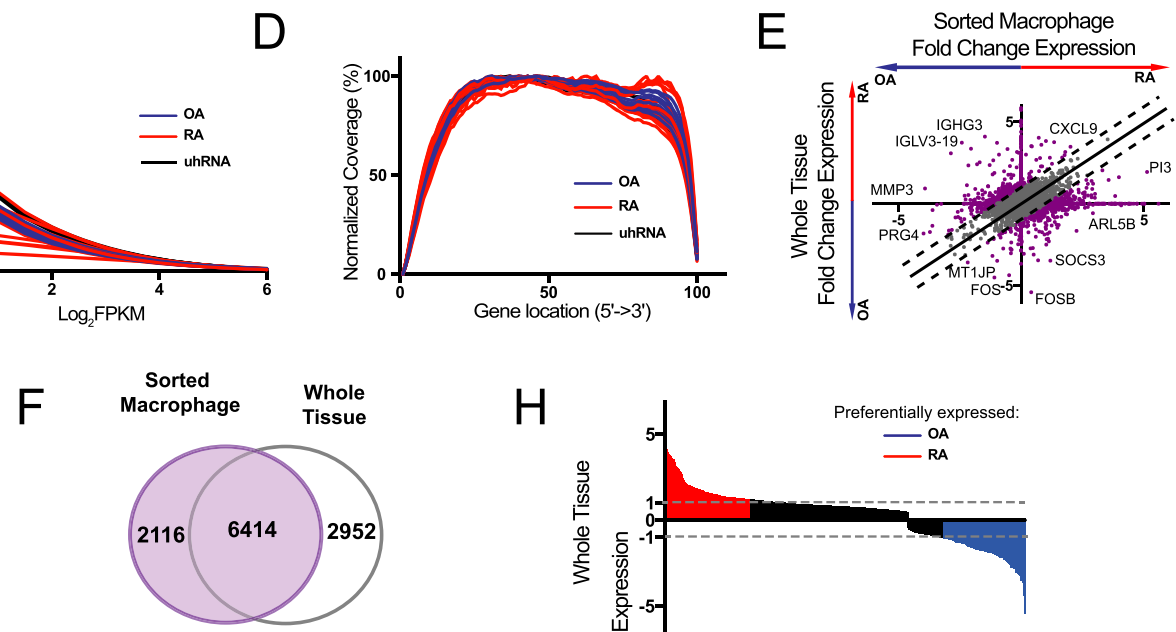

G
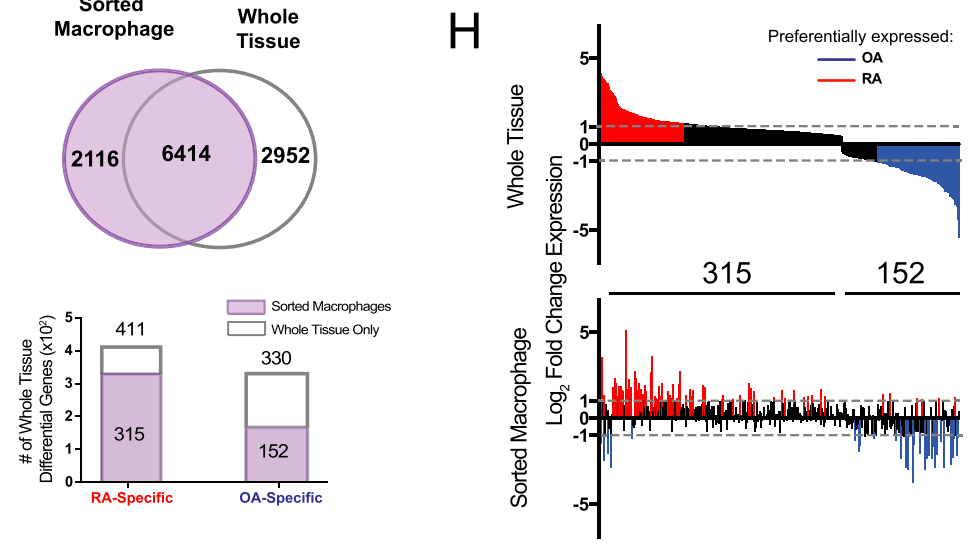

Figure 3. Isolation of synovial macrophages and macrophage-specific RNA sequencing. A, Gating strategy used to identify synovial macrophages in osteoarthritis (OA) and rheumatoid arthritis (RA) tissue. DC = dendritic cell. B, Optimization of the synovial tissue processing procedure. The success of tissue processing was evaluated by the number of viable, CD45+, and CD11b+ cells identified by flow cytometry. C, Number of genes with an expression level greater than a given $\log _{2}$ (fragments per kilobase per million [FPKM]) value for each OA, RA, and universal human RNA (uhRNA) control sample. D, Gene coverage plot displaying the average read density across genes from $5^{\prime}$ to $3^{\prime}$. E, Log fold change of gene expression between RA and OA whole tissue samples and macrophages. Broken lines indicate a difference of 1; solid line indicates no change in expression. Select genes are displayed. F, Venn diagram comparing numbers of genes expressed in sorted macrophages and whole tissue. G, Numbers of genes differentially expressed in whole tissue that were also detected in sorted macrophages from RA and OA samples. $\mathbf{H}, \mathrm{Log}_{2}$ fold change in expression of the 467 differentially expressed genes (in G) in whole tissue and sorted macrophages. Genes are ordered along the x-axis by decreasing fold change in whole tissue. The numbers of genes preferentially expressed in RA tissue $\left(\log _{2}\right.$ fold change $\left.>1\right)$ and $\mathrm{OA}$ tissue $\left(\log _{2}\right.$ fold change $<-1$ ) are indicated in red and blue, respectively. 
across the genome (Figure 2B). Nine RA synovial biopsy samples and 9 OA tissue samples produced high-quality RNA-seq libraries and were used for further analyses, concentrating on a set of 9,366 expressed genes. The global gene expression profiles from synovial tissue samples were heterogeneous across the RA samples and did not clearly cluster apart from the OA samples (Figure 2C). The variability among patients highlights the complexity in the presentation of RA in whole tissue and points to a shift in gene expression in individual cell types that could be associated with disease activity status and therapy at the time of biopsy.

Differential expression analysis identified genes that were specific to either RA or OA synovial tissue samples. We found 411 RA-specific genes and 330 OA-specific genes (Figure 2D). GO analysis revealed that RA-specific genes were associated with a wide range of immune processes, including leukocyte activation, T cell activation, and B cell-mediated immunity, while OA-specific genes were associated with more homeostatic processes, such as osteoblast differentiation, bone remodeling, and the epidermal growth factor receptor signaling pathway. Specifically, we found several macrophage-related genes (FCGR2A, IRF8, MyD88, and CD14) that were significantly up-regulated in RA relative to OA synovial tissue (Figure 2E). Genes that were preferentially expressed in OA, such as lubricin (58), JUN (59), ADAMTS1 (60), and SCRG1 (61), have previously been linked to differences in synovial tissue function in OA. The broad range of pathways involved in RA at the level of whole tissue highlights the need for a cell typespecific approach to better understand the role of particular cell populations.

Synovial macrophage digestion and RNA-seq analysis. Multiparameter flow cytometry was used to isolate macrophages from RA and OA synovial tissue (Figure 3A). Macrophages were gated via the inclusion of singlets, viable, CD45+, and HLA-DR+ cells. Macrophages were further isolated by excluding dendritic cells and then gating on the remaining HLA-DR+ cells followed by CD11b+ cells to identify the CD206+ macrophage populations. An optimized digestion protocol was developed to isolate viable macrophages from synovial tissue. The effectiveness of tissue digestion was assessed by maximizing the number of viable, CD45+, and $\mathrm{CD} 11 \mathrm{~b}+$ cells within a given single-cell suspension (Figure 3B). A mean \pm SEM of $1,642 \pm 1,178$ macrophages was isolated from digested biopsy samples and prepared for RNA-seq analysis (Table 1). An identical digestion protocol was used to isolate cell populations from OA synovial tissue as

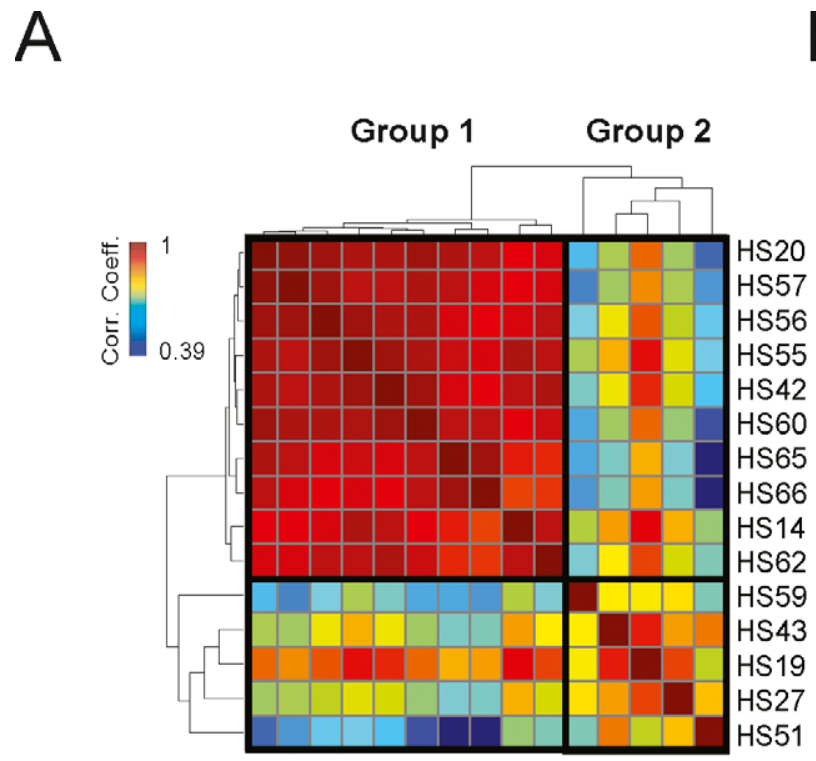

\begin{tabular}{|c|c|c|c|}
\hline Patient Information & P-value & Group 1 & Group 2 \\
\hline Disease Duration & 0.67 & 8.67 & 11.00 \\
\hline SJC & 0.03 & 5.78 & 11.00 \\
\hline TJC & 0.09 & 3.67 & 10.50 \\
\hline $\begin{array}{c}\text { Early Disease } \\
<2 \text { years }\end{array}$ & & $30 \%$ & $20 \%$ \\
\hline $\begin{array}{l}>2 \text { years } \\
\text { No Data }\end{array}$ & 0.99 & $\begin{array}{l}60 \% \\
10 \%\end{array}$ & $\begin{array}{r}80 \% \\
0 \%\end{array}$ \\
\hline \multicolumn{4}{|l|}{ Rheumatoid Factor } \\
\hline $\begin{array}{l}\text { Positive } \\
\text { Negative }\end{array}$ & 0.25 & $\begin{array}{l}80 \% \\
20 \%\end{array}$ & $\begin{array}{l}40 \% \\
60 \%\end{array}$ \\
\hline $\begin{array}{l}\text { Anti-CCP } \\
\text { Positive } \\
\text { Negative } \\
\text { No Data }\end{array}$ & 0.29 & $\begin{array}{l}60 \% \\
20 \% \\
20 \%\end{array}$ & $\begin{array}{c}20 \% \\
30 \% \\
0 \%\end{array}$ \\
\hline $\begin{array}{l}\text { Biologic } \\
\text { None }\end{array}$ & & $30 \%$ & $20 \%$ \\
\hline $\begin{array}{r}\text { Current } \\
\text { Past }\end{array}$ & 0.99 & $\begin{array}{l}60 \% \\
10 \%\end{array}$ & $\begin{array}{l}80 \% \\
0 \%\end{array}$ \\
\hline $\begin{array}{r}\text { Methotrexate } \\
\text { None } \\
\text { Current } \\
\text { Past }\end{array}$ & 0.99 & $\begin{array}{l}30 \% \\
40 \% \\
30 \%\end{array}$ & $\begin{array}{l}40 \% \\
40 \% \\
20 \%\end{array}$ \\
\hline
\end{tabular}

Figure 4. Analysis of global gene expression profiles in sorted macrophages from patients with rheumatoid arthritis. A, Pairwise Pearson's correlation of gene expression between individual patient samples. Samples are organized by hierarchical clustering based on their Pearson's correlation coefficients (corr. coeff.) across samples, forming 2 groups. HS20 = human sample 20. B, Table of association analysis of group 1 and group 2 (as defined in A) with clinical parameters. Values reflect either the group average (for continuous variables) or percent of patients (for categorical variables). $P$ values for disease duration, swollen joint count (SJC), and tender joint count (TJC) were determined by Student's $t$-test, and $P$ values for early disease, rheumatoid factor, anti-cyclic citrullinated peptide (anti-CCP) antibody, and treatment status were determined by Fisher's exact test. Significant values are shown in red. 
described above, resulting in an average of 77,414 macrophages per sample (Table 1).

Isolated macrophages from 15 RA biopsy samples and 9 OA tissue samples were collected and passed sequencing quality control for further analysis. The percent alignment of reads (average 54\%) was lower than in whole tissue (average $82 \%$ ) likely due to the increased noise of low input. There was a minimal difference in the number of genes detected in RA versus OA macrophages (Figure 3C). RA macrophages demonstrated comparable complexity (Table 1) and gene coverage (Figure 3D) to OA samples even though the number of RA macrophages was 45 times less than the number of sorted OA macrophages.

To determine whether RNA-seq data from macrophages provided additional information that could not be gleaned from the whole tissue data, we investigated the "macrophage-specific" gene expression profiles. A comparison of fold change in gene expression between RA and OA revealed differentially expressed genes that were detected only by whole tissue or only by macrophage-specific RNA-seq (Figure 3E). For example, genes associated with inflammatory arthritis, such as PI3 (62) and MMP3 (63), were preferentially expressed in RA and OA macrophages, respectively, while no change in expression was observed in whole tissue RNA-seq. Further comparison revealed that 6,414 genes were expressed in both data sets, while 2,952 genes were exclusively found in whole tissue, and 2,116 genes were macrophage specific (Figure 3F). Genes exclusively expressed by whole tissue were likely associated with other cell types, while macrophage-specific genes were likely below the limit of detection of whole tissue RNA-seq. Of the 411 RA-specific and 330 OA-specific genes from whole tissue (Figure 2D), 315 and 152, respectively, were expressed in the macrophagespecific data set (Figure 3G). However, many of these 467 genes were not differentially expressed in the same direction in the macrophage-specific data set (Figure 3H).

Next, we compared the global gene expression profiles from synovial macrophages across patients. We identified 2 distinct groups of RA patients based on gene expression profiles (Figure 4A). Group 1 consisted of twothirds of the patients (10 of 15$)$ with highly similar gene expression profiles, while group 2 contained the remaining 5 patients with divergent gene expression. Patients in group 2 exhibited significantly higher SJC than those in group $1(P=0.03)$. These findings demonstrate the possibility for cell type-specific transcriptional profiles of RA patients to provide information about disease severity.

Modules of co-regulated genes may represent pathways that perform specific functions in disease. To identify gene modules within the macrophage transcriptional profiles, we defined a subset of 553 genes as differentially expressed across 15 RA patients after accounting for noise and outliers (see Patients and Methods). These genes were clustered into 6 modules (modules 1-6) based on the similarity in their patterns of expression across patients (Figure 5A). We calculated the enrichment or depletion of each gene module within the expression profile of each patient to determine which patients were driving these modules (Figure 5B).

Despite the limited statistical power of a sample set of 15 patients, we were able to identify associations between the expression of these gene modules in patients and clinical parameters (Figures 5C and D). For example, expression levels of module 2 genes, including CCR1 and TREM2 (Figure 5E), were significantly increased (1.31 fold or $0.39 \log _{2}$ fold change; $P=0.05$ ) (Figure 5D) in patients who had stopped taking methotrexate. In addition, expression levels of genes in module 3 were negatively correlated with disease severity as measured by SJC $(P=0.007)$ and had 1.7-fold higher expression in patients recently diagnosed as having RA $\left(\log _{2}\right.$ fold change $=0.78$; $P=0.04$ ) (Figure 5D). Module 3 genes, such as NFKB1A and TIMP1, are involved in the cellular response to IL-1 as determined by GO enrichment (data are available upon request from the corresponding author). Module 4 genes were 1.7-fold more highly expressed in patients who were not taking a biologic medication at the time of biopsy $\left(\log _{2}\right.$ fold change $\left.=0.78 ; P=0.01\right)$. Module 4 was enriched with immune response genes such as TNF and MAFB (Figure 5E). Expression of module 5 genes, such as MIF and HMGB2, was positively associated with disease severity as measured by TJC $(P=0.03)$ (Figure $5 \mathrm{C})$. Genes in module 6, such as CD83 and CXCR4, were 2.0fold higher in patients who were negative for RF $\left(\log _{2}\right.$ fold change $=1.0 ; P=0.03$ ). Taken together, our data demonstrate for the first time that transcriptional profiling of isolated synovial macrophages obtained using ultrasound-guided synovial biopsies may be used to characterize patients in a biologically relevant manner.

\section{DISCUSSION}

Recent advances in ultrasound technology have opened up a new opportunity for rheumatologists to perform minimally invasive ultrasound-guided synovial tissue biopsies (25). While arthroplasty allows for the collection of large pieces of synovial tissue, using it as a method of obtaining tissue from RA patients for research purposes in the US and in a longitudinal manner is challenging $(23,29,41,45,64-67)$. Moreover, the tissue obtained from arthroplasty is usually late stage and may not reflect ongoing active disease, unlike tissue which may be obtained 

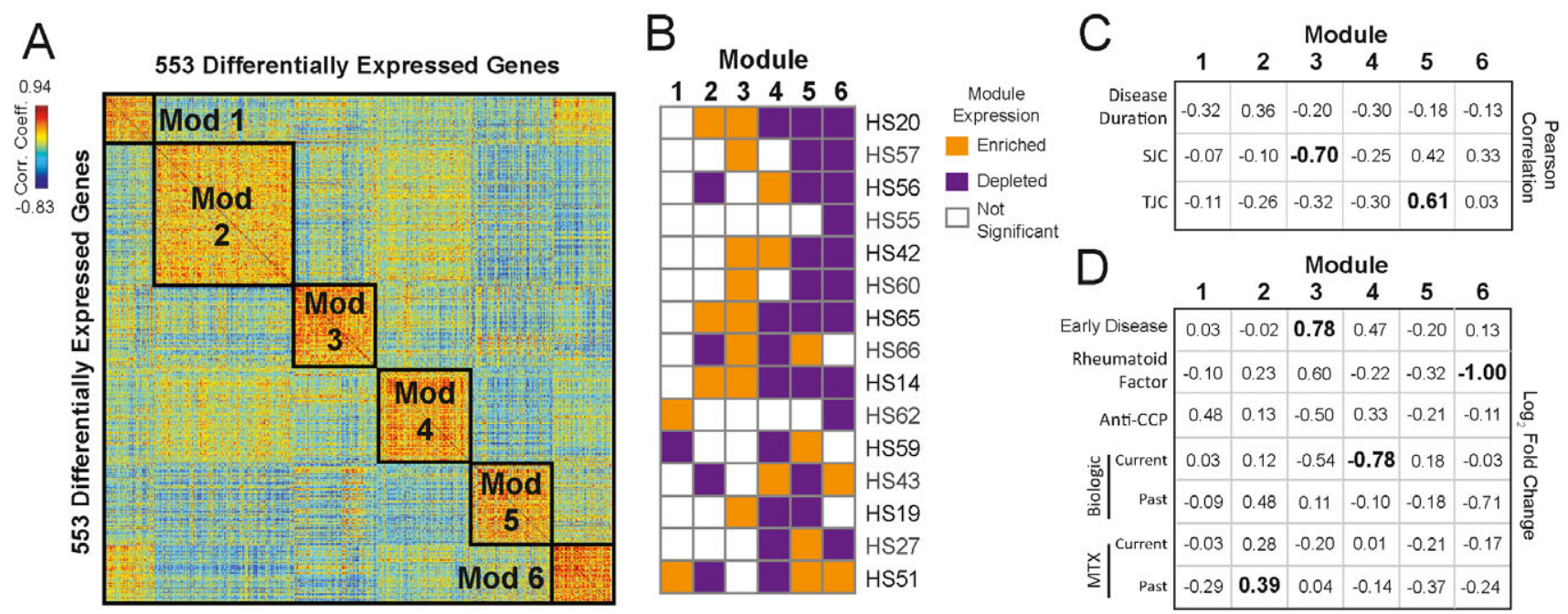

E

Mod 1

$\operatorname{Mod} 2$

Mod 3

Mod 4

Mod 5

Mod 6
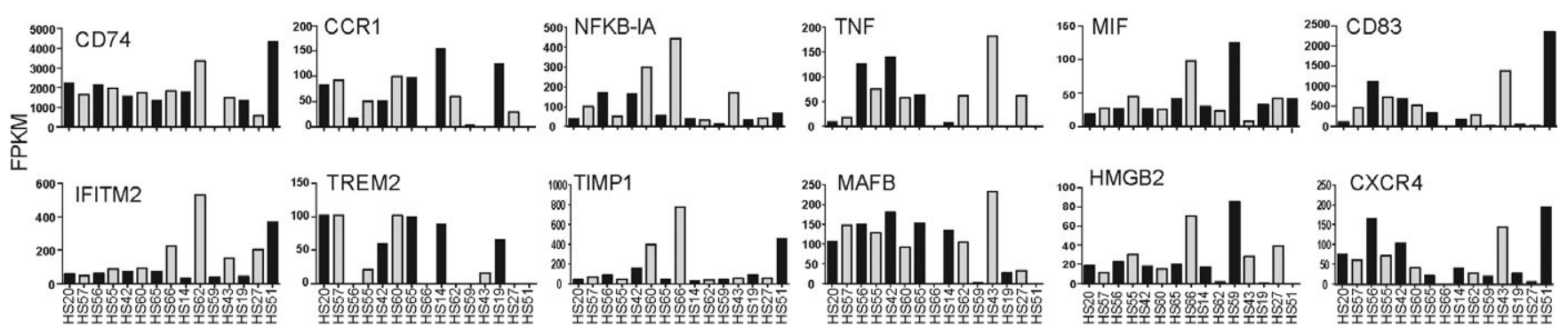

Figure 5. A, Pairwise Pearson's correlations between 553 differentially expressed genes across sorted macrophages from rheumatoid arthritis (RA) patients. Genes were clustered using K-means clustering, and 6 modules (mod) of co-regulated genes were identified. B, Expression of genes in each module in each patient. The Kolmogorov-Smirnov test was used to determine if genes were enriched or depleted $(P<0.05)$. C, Table of association displaying Pearson's correlations between the median expression of gene modules in patients and the given clinical parameters (continuous variables). Correlation coefficients (corr. coeff.) with a $P$ value less than 0.05 are shown in boldface. D, Table of association displaying the average fold change ( $\log _{2}$ fold change) between the median expression of gene modules in patients who were positive versus those who were negative for the indicated clinical parameters (categorical variables). Current treatment compares patients who were receiving the medication at the time of biopsy with those who were not receiving the medication at the time of biopsy. Past treatment compares patients who had stopped the medication with those who had never received the medication. Significant comparisons $(P<0.05$, by $t$-test $)$ are shown in boldface. E, Expression levels (fragments per kilobase per million [FPKM]) of individual genes selected across the 6 modules in patients with RA. HS20 = human sample 20; SJC = swollen joint count; TJC = tender joint count; anti-CCP = anti-cyclic citrullinated peptide; MTX = methotrexate.

using ultrasound-guided synovial biopsy. The fact that ultrasound-guided synovial biopsies may be performed in the clinic without a surgical suite and require minimal to no recovery time for the patient outweighs the smaller amount of tissue retrieved $(23,29,41,45,64-67)$. In fact, in several countries in Europe, this technique is used to obtain synovial tissue for research purposes in a large number of patients without significant complications (34-36,38-40,6873). The procedure itself is well accepted by both patients and referring rheumatologists in the US, at rates similar to those observed by our European colleagues $(34,36)$.

Previous studies have focused on access to the joint, intrajoint synovial variation, and reproducibility of measurements using the ultrasound-guided synovial biopsy technique (34-36). Furthermore, these biopsies do not appear to affect subsequent clinical or ultrasound disease activity assessments, which is important for patients who might subsequently enroll in clinical trials (74). European groups have also performed numerous studies to validate the needle biopsy and portal and forceps procedures and tissue sampling (34-36,38-40,68,75,76). Our data demonstrate that the ultrasound-guided synovial tissue biopsy specimens obtained from patients with RA are sufficient for RNA-seq, distinguish differences between patients with RA and those with OA, and, importantly, set the framework for the stratification of patients with RA according to the most prominent disease pathway. We also report an optimized digestion protocol for synovial tissue obtained by ultrasound-guided biopsies and demonstrate the ability to sort viable hematopoietic cells 
by FACS. Further, we show that only small numbers of cells (as few as 10 cells) are sufficient for generation of libraries for quality RNA-seq analysis. With our initial cohort of 41 patients, we have been able to link the cell type-specific transcriptional signatures with patients' treatment regimen and clinical information.

Currently, the standard of care for RA is to prescribe biologic therapy through a costly and time-consuming trial-and-error process. Therefore, the utility of a biomarker to identify how a patient will respond to a particular therapy cannot be overstated. While peripheral blood is attractive for identifying a potential biomarker due to its ease of attainability, this approach has not been fruitful. Early studies by Dr. Paul Tak and colleagues demonstrated the potential of obtaining synovial tissue as a means to determine a biomarker for responsiveness to therapy (31). In his seminal studies, he showed that a reduction in the number of synovial sublining macrophages correlates with a decrease in disease activity (i.e., the Disease Activity Score in 28 joints) (31). The abundance of synovial sublining macrophages is currently a leading candidate for a viable biomarker of therapeutic response in RA (25).

We posit that transcriptional signatures in macrophages regardless of location (sublining versus synovial lining) will predict responsiveness to specific non-biologic and/or biologic therapies. Our data suggest the existence of associations between the transcriptional signature of macrophages and treatment course (or patient compliance). However, the present study is limited in its ability to predict response to therapy because of the constraint of obtaining tissue at a single time point for each patient at different stages of disease. Future studies beyond the scope of the present one will entail collection of synovial biopsy specimens from a larger cohort longitudinally, prior to and following therapy. Therefore, this study serves as proof of the principle that transcriptional analysis of synovial macrophages using ultrasound-guided synovial biopsies may function to uncover novel pathways underlying disease pathogenesis or response to therapy. Currently, studies are also underway in the Accelerating Medicines Partnership which will take advantage of synovial biopsies for identification of molecular pathways (77).

In summary, this study is the first in the US to harness the potential of ultrasound-guided synovial biopsies as a method of obtaining synovial tissue from patients with RA. Based on the recent success of REASON using minimally invasive ultrasound-guided synovial biopsies, coupled with our ability to interrogate synovial tissue at multiple levels using cutting-edge technologies, we believe that future studies have the potential to provide critical information to rheumatologists in establishing precision medicine as a reality for our patients.

\section{ACKNOWLEDGMENTS}

In loving memory of Colleen Pope Vitu. We thank the patients who underwent synovial biopsy for this study and acknowledge technical assistance at each site. We thank Stephanie Ledbetter, MS, Laticia Woodruff, RN, and Keith Wanzeck, BS at University of Alabama at Birmingham. We also thank Drs. Terrance Peabody, Ali Shilatifard, Hussain Bhikhapurwala, and Danette Ko for their assistance. Flow cytometry cell sorting was performed in the Northwestern University Lurie Cancer Center Flow Cytometry Core Facility (supported by National Cancer Institute [NCI] P30-CA060553) and on a BD FACSAria SORP system (purchased through the support of National Institutes of Health 1S10OD011996-01). Histology services were provided by the Northwestern University Mouse Histology and Phenotyping Laboratory (supported by NCI P30CA060553 awarded to the Robert H. Lurie Comprehensive Cancer Center). RNA sequencing was performed in the Northwestern University Division of Rheumatology and Pulmonary and Critical Care sequencing facility.

\section{AUTHOR CONTRIBUTIONS}

All authors were involved in drafting the article or revising it critically for important intellectual content, and all authors approved the final version to be published. Dr. Perlman had full access to all of the data in the study and takes responsibility for the integrity of the data and the accuracy of the data analysis.

Study conception and design. Mandelin, Homan, Shaffer, Cuda, Dominguez, Bacalao, Carns, Hinchcliff, Lee, Aren, Thakrar, Montgomery, Bridges, Bathon, Atkinson, Fox, Matteson, Buckley, Pitzalis, Parks, Hughes, Geraldino-Pardilla, Ike, Phillips, Wright, Filer, Kelly, Ruderman, Morgan, Abdala-Valencia, Misharin, Budinger, Bartom, Pope, Perlman, Winter.

Acquisition of data. Mandelin, Homan, Shaffer, Cuda, Dominguez, Bacalao, Carns, Hinchcliff, Lee, Aren, Thakrar, Montgomery, Bridges, Bathon, Atkinson, Fox, Matteson, Buckley, Pitzalis, Parks, Hughes, Geraldino-Pardilla, Ike, Phillips, Wright, Filer, Kelly, Ruderman, Morgan, Abdala-Valencia, Misharin, Budinger, Bartom, Pope, Perlman, Winter. Analysis and interpretation of data. Mandelin, Homan, Shaffer, Cuda, Dominguez, Bacalao, Carns, Hinchcliff, Lee, Aren, Thakrar, Montgomery, Bridges, Bathon, Atkinson, Fox, Matteson, Buckley, Pitzalis, Parks, Hughes, Geraldino-Pardilla, Ike, Phillips, Wright, Filer, Kelly, Ruderman, Morgan, Abdala-Valencia, Misharin, Budinger, Bartom, Pope, Perlman, Winter.

\section{REFERENCES}

1. O'Dell JR, Curtis JR, Mikuls TR, Cofield SS, Bridges SL Jr, Ranganath VK, et al. Validation of the methotrexate-first strategy in patients with early, poor-prognosis rheumatoid arthritis: results from a two-year randomized, double-blind trial. Arthritis Rheum 2013;65:1985-94.

2. Saevarsdottir S, Wallin $H$, Seddighzadeh $M$, Ernestam S, Geborek P, Petersson IF, et al. Predictors of response to methotrexate in early DMARD naive rheumatoid arthritis: results from the initial open-label phase of the SWEFOT trial. Ann Rheum Dis 2011;70:469-75.

3. Bathon JM, Martin RW, Fleischmann RM, Tesser JR, Schiff MH, Keystone EC, et al. A comparison of etanercept and methotrexate in patients with early rheumatoid arthritis. N Engl J Med 2000;343:1586-93.

4. Breedveld FC, Weisman MH, Kavanaugh AF, Cohen SB, Pavelka $\mathrm{K}$, van Vollenhoven $\mathrm{R}$, et al. The PREMIER study: a multicenter, randomized, double-blind clinical trial of combination therapy with adalimumab plus methotrexate versus methotrexate 
alone or adalimumab alone in patients with early, aggressive rheumatoid arthritis who had not had previous methotrexate treatment. Arthritis Rheum 2006;54:26-37.

5. Emery P, Breedveld FC, Hall S, Durez P, Chang DJ, Robertson $\mathrm{D}$, et al. Comparison of methotrexate monotherapy with a combination of methotrexate and etanercept in active, early, moderate to severe rheumatoid arthritis (COMET): a randomised, doubleblind, parallel treatment trial. Lancet 2008;372:375-82.

6. Moreland LW, O'Dell JR, Paulus HE, Curtis JR, Bathon JM, St.Clair EW, et al. A randomized comparative effectiveness study of oral triple therapy versus etanercept plus methotrexate in early aggressive rheumatoid arthritis: the treatment of Early Aggressive Rheumatoid Arthritis trial. Arthritis Rheum 2012;64:2824-35.

7. Greenberg JD, Reed G, Decktor D, Harrold L, Furst D, Gibofsky A, et al. A comparative effectiveness study of adalimumab, etanercept and infliximab in biologically naive and switched rheumatoid arthritis patients: results from the US CORRONA registry. Ann Rheum Dis 2012;71:1134-42.

8. Hetland ML, Christensen IJ, Tarp U, Dreyer L, Hansen A, Hansen IT, et al. Direct comparison of treatment responses, remission rates, and drug adherence in patients with rheumatoid arthritis treated with adalimumab, etanercept, or infliximab: results from eight years of surveillance of clinical practice in the nationwide Danish DANBIO registry. Arthritis Rheum 2010;62:22-32.

9. Jobanputra P, Maggs F, Deeming A, Carruthers D, Rankin E, Jordan AC, et al. A randomised efficacy and discontinuation study of etanercept versus adalimumab (RED SEA) for rheumatoid arthritis: a pragmatic, unblinded, non-inferiority study of first TNF inhibitor use: outcomes over 2 years. BMJ Open 2012;2.

10. Markenson JA, Gibofsky A, Palmer WR, Keystone EC, Schiff $\mathrm{MH}$, Feng J, et al. Persistence with anti-tumor necrosis factor therapies in patients with rheumatoid arthritis: observations from the RADIUS registry. J Rheumatol 2011;38:1273-81.

11. Rendas-Baum R, Wallenstein GV, Koncz T, Kosinski M, Yang M, Bradley J, et al. Evaluating the efficacy of sequential biologic therapies for rheumatoid arthritis patients with an inadequate response to tumor necrosis factor- $\alpha$ inhibitors. Arthritis Res Ther 2011;13:R25

12. Helmick CG, Felson DT, Lawrence RC, Gabriel S, Hirsch R, Kwoh CK, et al. Estimates of the prevalence of arthritis and other rheumatic conditions in the United States. Part I. Arthritis Rheum 2008;58:15-25.

13. Myasoedova E, Crowson CS, Kremers HM, Therneau TM, Gabriel SE. Is the incidence of rheumatoid arthritis rising? Results from Olmsted County, Minnesota, 1955-2007. Arthritis Rheum 2010;62: 1576-82.

14. Chamberlain ND, Kim SJ, Vila OM, Volin MV, Volkov S, Pope RM, et al. Ligation of TLR7 by rheumatoid arthritis synovial fluid single strand RNA induces transcription of TNF $\alpha$ in monocytes. Ann Rheum Dis 2013;72:418-26.

15. Huang Q, Pope RM. Toll-like receptor signaling: a potential link among rheumatoid arthritis, systemic lupus, and atherosclerosis. J Leukoc Biol 2010;88:253-62.

16. Duffau P, Menn-Josephy H, Cuda CM, Dominguez S, Aprahamian TR, Watkins AA, et al. Promotion of inflammatory arthritis by interferon regulatory factor 5 in a mouse model. Arthritis Rheumatol 2015;67:3146-57.

17. Huang QQ, Koessler RE, Birkett R, Perlman H, Xing L, Pope RM. TLR2 deletion promotes arthritis through reduction of IL-10. J Leukoc Biol 2013;93:751-9.

18. Palmer G, Chobaz V, Talabot-Ayer D, Taylor S, So A, Gabay C, et al. Assessment of the efficacy of different statins in murine collagen-induced arthritis. Arthritis Rheum 2004;50:4051-9.

19. Nuki G, Bresnihan B, Bear MB, McCabe D. Long-term safety and maintenance of clinical improvement following treatment with anakinra (recombinant human interleukin-1 receptor antagonist) in patients with rheumatoid arthritis: extension phase of a randomized, double-blind, placebo-controlled trial. Arthritis Rheum 2002;46: 2838-46.
20. Genovese MC, Bathon JM, Martin RW, Fleischmann RM, Tesser JR, Schiff MH, et al. Etanercept versus methotrexate in patients with early rheumatoid arthritis: two-year radiographic and clinical outcomes. Arthritis Rheum 2002;46:1443-50.

21. De Rycke L, Baeten D, Foell D, Kruithof E, Veys EM, Roth J, et al. Differential expression and response to anti-TNF $\alpha$ treatment of infiltrating versus resident tissue macrophage subsets in autoimmune arthritis. J Pathol 2005;206:17-27.

22. Barland P, Novikoff AB, Hamerman D. Electron microscopy of the human synovial membrane. J Cell Biol 1962;14:207-20.

23. Filkova M, Cope A, Mant T, Galloway J. Is there a role of synovial biopsy in drug development? BMC Musculoskelet Disord 2016;17:172.

24. Sieberts SK, Zhu F, Garcia-Garcia J, Stahl E, Pratap A, Pandey $\mathrm{G}$, et al. Crowdsourced assessment of common genetic contribution to predicting anti-TNF treatment response in rheumatoid arthritis. Nat Commun 2016;7:12460.

25. Udalova IA, Mantovani A, Feldmann M. Macrophage heterogeneity in the context of rheumatoid arthritis. Nat Rev Rheumatol 2016;12:472-85.

26. De Hair MJ, van de Sande MG, Ramwadhdoebe TH, Hansson M, Landewé R, van der Leij C, et al. Features of the synovium of individuals at risk of developing rheumatoid arthritis: implications for understanding preclinical rheumatoid arthritis. Arthritis Rheumatol 2014;66:513-22.

27. Gerlag D, Tak PP. Synovial biopsy. Best Pract Res Clin Rheumatol 2005; $19: 387-400$.

28. Gerlag DM, Tak PP. How useful are synovial biopsies for the diagnosis of rheumatic diseases? Nat Clin Pract Rheumatol 2007;3:248-9.

29. Gerlag DM, Tak PP. How to perform and analyse synovial biopsies. Best Pract Res Clin Rheumatol 2013;27:195-207.

30. Haringman JJ, Vinkenoog $M$, Gerlag DM, Smeets TJ, Zwinderman AH, Tak PP. Reliability of computerized image analysis for the evaluation of serial synovial biopsies in randomized controlled trials in rheumatoid arthritis. Arthritis Res Ther 2005;7:R862-7.

31. Jahangier ZN, Jacobs JW, Kraan MC, Wenting MJ, Smeets TJ, Bijlsma JW, et al. Pretreatment macrophage infiltration of the synovium predicts the clinical effect of both radiation synovectomy and intra-articular glucocorticoids. Ann Rheum Dis 2006; 65:1286-92.

32. Kraan MC, Reece RJ, Smeets TJ, Veale DJ, Emery P, Tak PP. Comparison of synovial tissues from the knee joints and the small joints of rheumatoid arthritis patients: implications for pathogenesis and evaluation of treatment. Arthritis Rheum 2002;46: 2034-8.

33. Koski JM, Hammer HB. Ultrasound-guided procedures: techniques and usefulness in controlling inflammation and disease progression. Rheumatology (Oxford) 2012;51 Suppl 7:vii31-5.

34. Humby F, Kelly S, Bugatti S, Manzo A, Filer A, Mahto A, et al. Evaluation of minimally invasive, ultrasound-guided synovial biopsy techniques by the OMERACT filter: determining validation requirements. J Rheumatol 2016;43:208-13.

35. Humby F, Kelly S, Hands R, Rocher V, DiCicco M, Ng N, et al. Use of ultrasound-guided small joint biopsy to evaluate the histopathologic response to rheumatoid arthritis therapy: recommendations for application to clinical trials. Arthritis Rheumatol 2015;67:2601-10.

36. Kelly S, Humby F, Filer A, Ng N, Di Cicco M, Hands RE, et al. Ultrasound-guided synovial biopsy: a safe, well-tolerated and reliable technique for obtaining high-quality synovial tissue from both large and small joints in early arthritis patients. Ann Rheum Dis 2015;74:611-7.

37. Koski JM, Helle M. Ultrasound guided synovial biopsy using portal and forceps. Ann Rheum Dis 2005;64:926-9.

38. Lazarou I, D’Agostino MA, Naredo E, Humby F, Filer A, Kelly SG. Ultrasound-guided synovial biopsy: a systematic review according to the OMERACT filter and recommendations for 
minimal reporting standards in clinical studies. Rheumatology (Oxford) 2015;54:1867-75.

39. Ramírez J, Celis R, Usategui A, Ruiz-Esquide V, Faré R, Cuervo A, et al. Immunopathologic characterization of ultrasounddefined synovitis in rheumatoid arthritis patients in clinical remission. Arthritis Res Ther 2015;18:74.

40. Scirè CA, Epis O, Codullo V, Humby F, Morbini P, Manzo A, et al. Immunohistological assessment of the synovial tissue in small joints in rheumatoid arthritis: validation of a minimally invasive ultrasound-guided synovial biopsy procedure. Arthritis Res Ther 2007;9:R101.

41. Sitt JC, Griffith JF, Wong P. Ultrasound-guided synovial biopsy. Br J Radiol 2016;89:20150363.

42. Van Vugt RM, van Dalen A, Bijlsma JW. Ultrasound guided synovial biopsy of the wrist. Scand J Rheumatol 1997;26:212-4.

43. Filer A, de Pablo P, Allen G, Nightingale P, Jordan A, Jobanputra $P$, et al. Utility of ultrasound joint counts in the prediction of rheumatoid arthritis in patients with very early synovitis. Ann Rheum Dis 2011;70:500c7.

44. Filkova M, Aradi B, Senolt L, Ospelt C, Vettori S, Mann H, et al. Association of circulating miR-223 and miR-16 with disease activity in patients with early rheumatoid arthritis. Ann Rheum Dis 2014;73:1898-904.

45. Pitzalis C, Kelly S, Humby F. New learnings on the pathophysiology of RA from synovial biopsies. Curr Opin Rheumatol 2013; 25:334-44.

46. Yeo L, Toellner KM, Salmon M, Filer A, Buckley CD, Raza K, et al. Cytokine mRNA profiling identifies B cells as a major source of RANKL in rheumatoid arthritis. Ann Rheum Dis 2011;70:2022-8.

47. Arnett FC, Edworthy SM, Bloch DA, McShane DJ, Fries JF, Cooper NS, et al. The American Rheumatism Association 1987 revised criteria for the classification of rheumatoid arthritis. Arthritis Rheum 1988;31:315-24.

48. Aletaha D, Neogi T, Silman AJ, Funovits J, Felson DT, Bingham CO III, et al. 2010 rheumatoid arthritis classification criteria: an American College of Rheumatology/European League Against Rheumatism collaborative initiative. Arthritis Rheum 2010;62: 2569-81.

49. Singh JA, Saag KG, Bridges SL Jr, Akl EA, Bannuru RR, Sullivan MC, et al. 2015 American College of Rheumatology guideline for the treatment of rheumatoid arthritis. Arthritis Rheumatol 2016; 68:1-26.

50. Singh JA, Saag KG, Bridges SL Jr, Akl EA, Bannuru RR, Sullivan MC, et al. 2015 American College of Rheumatology guideline for the treatment of rheumatoid arthritis. Arthritis Care Res (Hoboken) 2016;68:1-25.

51. Wakefield RJ, Balint PV, Szkudlarek M, Filippucci E, Backhaus M, D'Agostino MA, et al. Musculoskeletal ultrasound including definitions for ultrasonographic pathology. J Rheumatol 2005;32: $2485-7$.

52. Kim D, Pertea G, Trapnell C, Pimentel H, Kelley R, Salzberg SL. TopHat2: accurate alignment of transcriptomes in the presence of insertions, deletions and gene fusions. Genome Biol 2013;14:R36.

53. Wang L, Wang S, Li W. RSeQC: quality control of RNA-seq experiments. Bioinformatics 2012;28:2184-5.

54. Anders S, Pyl PT, Huber W. HTSeq: a Python framework to work with high-throughput sequencing data. Bioinformatics 2015;31: 166-9.

55. Robinson MD, McCarthy DJ, Smyth GK. edgeR: a Bioconductor package for differential expression analysis of digital gene expression data. Bioinformatics 2010;26:139-40.

56. McCarthy DJ, Chen Y, Smyth GK. Differential expression analysis of multifactor RNA-Seq experiments with respect to biological variation. Nucleic Acids Res 2012;40:4288-97.

57. Eden E, Navon R, Steinfeld I, Lipson D, Yakhini Z. GOrilla: a tool for discovery and visualization of enriched GO terms in ranked gene lists. BMC Bioinformatics 2009;10:48.
58. Ruan MZ, Erez A, Guse K, Dawson B, Bertin T, Chen Y, et al. Proteoglycan 4 expression protects against the development of osteoarthritis. Sci Transl Med 2013;5:176ra34.

59. Zhang X, Yuan Z, Cui S. Identifying candidate genes involved in osteoarthritis through bioinformatics analysis. Clin Exp Rheumatol 2016;34:282-90.

60. Nagase H, Kashiwagi M. Aggrecanases and cartilage matrix degradation. Arthritis Res Ther 2003;5:94-103.

61. Ochi K, Derfoul A, Tuan RS. A predominantly articular cartilageassociated gene, SCRG1, is induced by glucocorticoid and stimulates chondrogenesis in vitro. Osteoarthritis Cartilage 2006;14:30-8.

62. Li J, Hsu HC, Mountz JD. Managing macrophages in rheumatoid arthritis by reform or removal. Curr Rheumatol Rep 2012;14: $445-54$

63. Han Z, Boyle DL, Manning AM, Firestein GS. AP-1 and NF-кB regulation in rheumatoid arthritis and murine collagen-induced arthritis. Autoimmunity 1998;28:197-208.

64. Humby FC, Al Balushi F, Lliso G, Cauli A, Pitzalis C. Can synovial pathobiology integrate with current clinical and imaging prediction models to achieve personalized health care in rheumatoid arthritis? Front Med (Lausanne) 2017;4:41.

65. Orr C, Vieira-Sousa E, Boyle DL, Buch MH, Buckley CD, Canete JD, et al. Synovial tissue research: a state-of-the-art review. Nat Rev Rheumatol 2017;13:630.

66. Van de Sande MG, Gerlag DM, Lodde BM, van Baarsen LG, Alivernini S, Codullo V, et al. Evaluating antirheumatic treatments using synovial biopsy: a recommendation for standardisation to be used in clinical trials. Ann Rheum Dis 2011;70:423-7.

67. Wechalekar MD, Smith MD. Utility of arthroscopic guided synovial biopsy in understanding synovial tissue pathology in health and disease states. World J Orthop 2014;5:566-73.

68. Najm A, Orr C, Heymann MF, Bart G, Veale DJ, Le Goff B. Success rate and utility of ultrasound-guided synovial biopsies in clinical practice. J Rheumatol 2016;43:2113-9.

69. Sitt JC, Griffith JF, Lai FM, Hui M, Chiu KH, Lee RK, et al. Ultrasound-guided synovial Tru-cut biopsy: indications, technique, and outcome in 111 cases. Eur Radiol 2017;27:2002-2010.

70. De Groof A, Ducreux J, Humby F, Nzeusseu Toukap A, Badot V, Pitzalis $\mathrm{C}$, et al. Higher expression of $\mathrm{TNF} \alpha$-induced genes in the synovium of patients with early rheumatoid arthritis correlates with disease activity, and predicts absence of response to first line therapy. Arthritis Res Ther 2016;18:19.

71. Kelly S, Bombardieri M, Humby F, Ng N, Marrelli A, Riahi S, et al. Angiogenic gene expression and vascular density are reflected in ultrasonographic features of synovitis in early rheumatoid arthritis: an observational study. Arthritis Res Ther 2015;17:58.

72. Frank-Bertoncelj M, Trenkmann M, Klein K, Karouzakis E, Rehrauer H, Bratus A, et al. Epigenetically-driven anatomical diversity of synovial fibroblasts guides joint-specific fibroblast functions. Nat Commun 2017;8:14852.

73. Luukkonen J, Pascual LM, Patlaka C, Lang P, Turunen S, Halleen $\mathrm{J}$, et al. Increased amount of phosphorylated proinflammatory osteopontin in rheumatoid arthritis synovia is associated to decreased tartrate-resistant acid phosphatase 5B/5A ratio. PLoS One 2017;12:e0182904.

74. Lazarou I, Kelly S, Humby F, Di Cicco M, Zou L, Rocher-Ros V, et al. Ultrasound-guided synovial biopsy of the wrist does not alter subsequent clinical or ultrasound disease activity assessments: a prospective study for incorporation of imaging in clinical trials. Clin Exp Rheumatol 2016;34:802-7.

75. Choi IY, Karpus ON, Turner JD, Hardie D, Marshall JL, de Hair MJ, et al. Stromal cell markers are differentially expressed in the synovial tissue of patients with early arthritis. PLoS One 2017;12: e0182751.

76. Filer A, Ward LS, Kemble S, Davies CS, Munir H, Rogers R, et al. Identification of a transitional fibroblast function in very early rheumatoid arthritis. Ann Rheum Dis 2017;76:2105-12.

77. Accelerating Medicines Partnership (AMP). URL: https://www. nih.gov/research-training/accelerating-medicines-partnership-amp. 